\title{
MOBBING: ANÁLISIS PSICOLEGAL Y ESTUDIO JURISPRUDENCIAL COMPARADO ENTRE ESPAÑA Y LATINOAMÉRICA
}

\author{
MOBBING: PSYCHOLEGAL ANALYSIS AND CASE LAW REVIEW \\ BETWEEN SPAIN AND LATIN AMERICA
}

VÍCTOR DUJO LÓPEZ

\author{
Universidad Complutense de Madrid, \\ España. \\ *Correspondencia: \\ victordujopsfagmail.com
}

\section{DAVID GONZÁLEZ-TRIJUEQUE}

Universidad Francisco de Vitoria, España.
FRANCISCO MAFFIOLETTI CELEDÓN

Universidad Diego Portales, Chile.
El acoso laboral o mobbing es un fenómeno creciente que ocasiona un profundo impacto tanto en las víctimas que lo sufren como en las organizaciones y la sociedad. Aunque tradicionalmente ha sido estudiado desde la Psicología del Trabajo y de las Organizaciones, la cada vez mayor presencia en los tribunales de víctimas de acoso ha despertado el interés de la Psicología Forense por su estudio en materia de victimología. Esto implica la necesidad de conocer la operativización del constructo tanto en su dimensión jurídica como psicológica. En el presente trabajo se pretenden abordar los principales elementos de la evaluación forense del acoso y repasar el marco legal español y latinoamericano. Además, se ha realizado un estudio de jurisprudencia para conocer el tratamiento jurídico del mobbing en los tribunales españoles.

Se concluye que entre los elementos más importantes que influyen en las resoluciones judiciales se encuentran la delimitación de la naturaleza y temporalidad del estresor y el nexo causal con los bienes jurídicos lesionados. El informe pericial psicológico, como medio probatorio, tiene relevancia a la hora de precisar el daño psíquico, descartar simulación, valorar vulnerabilidad (concausas) y establecer la causalidad entre el estresor y la psicopatología que experimenta la víctima.

Palabras clave: acoso laboral, jurisprudencia, victimología, daño psíquico
Workplace harassment or mobbing is a growing phenomenon with a deep impact both on the victims themselves as well as on organizations and society in general. While traditionally it has been studied from the perspective of Work and Organizational Psychology, the increasing cases of mobbing victims in courts have raised awareness of its study by Forensic Psychology in terms of victimology. This implies the need to understand the conceptualization of the construct in both legal and psychological dimensions. This paper aims to approach the main aspects of the forensic evaluation of harassment and review the Spanish and Latin American legal frameworks. In addition, a study of case law has been carried out to understand the legal approach to mobbing in Spanish courts.

We conclude that among the most significant factors affecting court decisions are the delimitation of the nature and duration of the stressor as well as the causal link to the injured legal assets. The expert psychological assessment, as evidence, is of relevance to define the psychological harm, dismiss simulation, determine vulnerability (aggravating factors) and prove causality between the stressor and the victim's symptoms.

Keywords: mobbing, case law, victimology, psychological injury 


\section{INTRODUCCIÓN}

La modernización económica y la globalización han tenido un impacto profundo en los sistemas de producción y las relaciones humanas en el trabajo, lo que ha implicado, en ocasiones, una precarización de las garantías y las condiciones laborales de los trabajadores. Las crisis económicas y el posfordismo generan un trasfondo de inestabilidad e inseguridad laboral que sitúan al trabajador en una posición de vulnerabilidad y desprotección. Estos cambios conllevan nuevas formas de interacción y comunicación que, a priori, aportan aspectos positivos en materia de eficacia y progreso, pero que pueden favorecer igualmente la aparición de nuevas fuentes de discriminación y una mayor complejidad en las relaciones laborales (Camacho-Ramírez, 2018).

El mobbing es considerado como uno de los riesgos psicosociales con mayor prevalencia dentro de la población laboral activa (Zapf y Einarsen, 2001). Se trata de un fenómeno que no ocurre como acción directa de variables relacionadas con la tarea a realizar, sino que tiene su base en las relaciones interpersonales que se constituyen en el contexto laboral (Martín-Daza, PérezBilbao y García-López, 1998).

No existe una única definición en el ámbito internacional, pero sí un consenso a la hora de delimitar cuáles son los elementos que configuran su conceptualización (Leymann, 1996). El acoso psicológico es un conjunto de acciones hostiles llevadas a cabo por un trabajador o varios trabajadores hacia un tercero. Este tipo de acciones negativas se dan en el contexto laboral (relación funcional) y se desarrollan de manera reiterada, frecuente y sistemática lal menos una vez a la semana durante al menos seis meses) lo que coloca a la víctima en una posición de vulnerabilidad e indefensión. A este planteamiento hay que sumar que dicho proceso se da habitualmente en un desequilibrio de poder formal o informal y precisa de la existencia de una finalidad destructiva (tendenciosidad) (Einarsen, Hoel, Zapf y Cooper, 2020).

El impacto del mobbing trasciende a la propia víctima hasta convertirse en un problema con elevados costes para empresas, administraciones y para la sociedad (Dujo, González-Trijueque y García-López, 2019). La Unión General de Trabajadores (UGT, 2013) estimó que entre el $11 \%$ y el $27 \%$ de los trastornos mentales estaban asociados a las condiciones laborales, lo que implicó un coste de entre 150 y 372 millones de euros en el 2011 (Agencia Europea para la Seguridad y la Salud en el Trabajo [EU OSHA], 2014).

En relación a la prevalencia, la gran heterogeneidad de los datos registrados a nivel global tiene su explicación en dos cuestiones clave: el método de medición y las diferencias socioculturales. En este sentido el contexto y los factores sociales pueden influir en la normalización, la identificación y el consecuente reporte de las conductas de acoso. La tolerancia hacia la violencia, la cultura de la individualización o la distancia de poder pueden influir en la validación de ciertas conductas (León-Pérez, Escartín y Giorgi, 2019; Zapf et al., 2020).

Paradójicamente, en países con una mayor concienciación del problema (más información, formación y medidas preventivas) puede darse una mayor identificación, lo que hace que aumenten las cifras de prevalencia. En cambio, en países con un tejido laboral más precario, y menor desarrollo de las políticas y medios de prevención de riesgos laborales, pueden darse cifras encubiertas debido al escaso conocimiento y concienciación de la población trabajadora (León-Pérez et al., 2019). 
En España, los datos de prevalencia dibujan una horquilla que va desde un 5,84\% (Carnero, Martínez y Sánchez-Mangas, 2012) hasta un 9\% (Dujo et al., 2020), y un 15\% (Arenas et al., 2015). Los datos de prevalencia en Latinoamérica están condicionados por la ausencia de estudios, la precariedad de algunos sectores laborales (condiciones y derechos laborales) y un menor desarrollo e integración del fenómeno mobbing en el tejido social y político. Los datos de prevalencia en Chile arrojan un 18\% de prevalencia según el estudio de Salas et al. (2015) con una muestra de mineros. En cambio, en Brasil, da SilvaJoão y Saldanha-Portelada (2016) señalan un 22,5\% de prevalencia. En el contexto europeo, Eurofound (2017), en su Sexta Encuesta Europea sobre Condiciones de Trabajo, calculó que un $5 \%$ de trabajadores habían sufrido acoso durante los últimos 12 meses.

Es necesario remarcar que dentro de la gran diversidad de términos que hacen referencia al acoso, en el corpus teórico y empírico internacional, los términos más habituales son mobbing, bullying y workplace bullying. En el contexto jurídico y en países hispanohablantes, es frecuente la aparición de la terminología mobbing, hostigamiento, acoso laboral, acoso psicológico y acoso moral como conceptos que engloban la misma realidad (Dujo, 2021).

El mobbing es un proceso complejo y multidimensional, lo que implica que cada caso se ha de evaluar de manera individualizada, tanto desde el punto de vista psicológico (victimología), como jurídico. En este sentido, no todos los elementos constitutivos tienen la misma importancia o gravedad. Para la mayoría de los autores las acciones asociadas con el abuso emocional constituyen el elemento central y diferenciador del acoso (Davenport, Schwartz y Elliot, 2005; Escartín,
Rodríguez-Carballeira, Zapf, Porrúa y Martín-Peña, 2009). En materia de victimología, además de la naturaleza de las conductas, se ha de tener en cuenta su repetición y sistematicidad, ya que este desarrollo en forma de microtraumatismos confiere a una serie de conductas, en esencia anodinas, el potencial lesivo que deriva en el daño psíquico de la víctima tras desgastar sus mecanismos de afrontamiento (Dujo, GonzálezTrijueque, Graña y Andreu,2020; Escartín, RodríguezCarballeira y Zapf, 2012).

Los juristas tienen un importante reto en la valoración legal del acoso. El carácter íntimo de las conductas hace que en la mayoría de las ocasiones solo se tenga el testimonio de la presunta víctima como prueba indiciaria. Además, la complejidad en la demostración jurídica del acoso se vertebra en el papel de la percepción de la víctima y en el elemento subjetivo de la tendenciosidad del perpetrador. Para dar respuesta a la necesidad de asistencia técnica de los tribunales, el psicólogo forense, desde el paradigma de la evaluación del daño psíquico, tiene la función de determinar el estresor potencialmente traumático, el alcance de la lesión o la secuela psíquica, y establecer el nexo causal entre ambos (Dujo y González-Trijueque, 2021).

El acoso laboral, como estresor potencialmente traumático, se ha convertido en un fenómeno cada vez más habitual en los tribunales. Esta problemática obliga a los profesionales de la psicología forense a sofisticar los procedimientos de evaluación debido a la complejidad de la victimización interpersonal y a las particularidades de la violencia en el contexto laboral lentorno formal, el papel del poder y el estatus, el apoyo social percibido, etc.). El objetivo del presente artículo es exponer el marco regulador del acoso laboral en España y Latinoamérica, los 
principales criterios jurídicos que subyacen a las resoluciones de los tribunales en el tratamiento del acoso y, por último, los principales pilares metodológicos y conceptuales del informe pericial como medio de prueba científico que tiene como función responder a las demandas de los operadores jurídicos en materia psicológica.

\section{MÉTODO}

\section{Procedimiento}

Para conceptualizar el mobbing desde el punto de vista psicológico y jurídico se ha realizado una revisión bibliográfica en base a criterios formales (bases de datos indexadas y utilización de referencias extraídas de los artículos primarios) y criterios informales. Para la conceptualización psicológica se han buscado libros, tesis y artículos en el campo de la Psicología del Trabajo y de las Organizaciones, y en el área de la Psicología Clínica, Legal y Forense sin ningún tipo de restricción temporal, aunque se ha dado prioridad en la inclusión a las referencias primarias que se hayan publicado en lo últimos diez años. Para la conceptualización jurídica se han buscado libros, artículos y tesis pertenecientes al campo del Derecho Laboral comparado. En un segundo paso, para el estudio de las repercusiones forenses, se han analizado sentencias del Tribunal Supremo español para estudiar el tratamiento que recibe el mobbing a nivel jurisprudencial. Se ha utilizado de referencia las directrices PRISMA (Liberati et al., 2009). La revisión se realizó entre abril y diciembre de 2021.

\section{Estrategias de búsqueda}

Para localizar los artículos se ha utilizado la base de datos especializada PsycINFO y el metabuscador Google
Académico. Los términos de búsqueda introducidos han sido los más empleados en la literatura especializada en castellano: “acoso laboral”, “acoso psicológico", "mobbing" "bullying" y "acoso moral" (términos principales de búsquedal y se han combinado con los operadores booleanos "AND" e "Y" y los términos “doctrina”, “jurisprudencia” “España” “Latinoamérica”, “Chile”, “Colombia”, “Uruguay”, “Brasil” y “Argentina”. Para matizar la búsqueda se han utilizado los conectores "WITH" y "SAME" entre los términos principales de búsqueda y los términos "doctrina”, “legislación” y “jurisprudencia”.

Para llevar a cabo la revisión de sentencias se ha utilizado la base de datos jurídicos Aranzadi Westlaw, realizando una limitación temporal que va desde el 1 de junio de 2010 al 1 de enero de 2020, introduciendo los marcadores "mobbing”, “acoso laboral”, “acoso psicológico" y "acoso moral". El tipo de resolución seleccionada ha sido "sentencia". En el campo de "jurisdicción/procedimiento" se introdujo la opción "social”, "contencioso-administrativa", "civil" y "penal”. Todas las sentencias analizadas son del Tribunal Supremo español.

\section{Criterios de inclusión}

Se han utilizado los documentos más actualizados en materia legislativa, regulación jurídica y práctica aplicativa. Para la conceptualización psicológica y jurídica del acoso laboral se han seleccionado como artículos primarios los publicados en los últimos diez años. Dentro de los artículos primarios se ha acudido al apartado de las referencias para seleccionar artículos (sin delimitación temporall que fueran de relevancia para la conceptualización del constructo. Los artículos deben estar publicados en revistas indexadas y de revisión por pares. 
Para el análisis jurídico, debido al carácter cambiante de las leyes y la naturaleza dinámica de la doctrina y jurisprudencia, se han buscado documentos publicados en los últimos diez años.

En cuanto a las sentencias, se han considerado relevantes aquellas que reflejan los criterios utilizados por el tribunal en relación al mobbing. Debido a la escasez de resoluciones que confirman la existencia de acoso laboral en el Tribunal Supremo español, se han seleccionado aquellas que lo contemplan y aquellas que, aunque rechazan la existencia de acoso laboral, fundamentan su razonamiento en base a los criterios psicológicos y jurídicos del constructo.

\section{Criterios de exclusión}

Debido a que el presente estudio pretende actualizar la literatura existente acerca del mobbing y su abordaje psicolegal, se han excluido los documentos con contenido obsoleto (leyes derogadas). En cuanto al análisis jurisprudencial del Tribunal Supremo español se han excluido todas las sentencias solapadas y aquellas cuyo contenido era tangencial o irrelevante para el objetivo del presente estudio. Cuando las explicaciones relativas al mobbing son generalistas y no forman parte de la fundamentación jurídica de la resolución, la sentencia queda excluida.

\section{Muestra de sentencias}

Con los parámetros expuestos se han obtenido un total de 255 sentencias. Del total en bruto se ha considerado que 32 eran relevantes para el presente estudio. Para que una sentencia sea relevante debe cumplir los siguientes criterios:

* Que se demuestre la existencia de mobbing
* Que se fundamenten los criterios operativos del mobbing (naturaleza, criterio temporal, relación funcional y tendenciosidad)

* Si no se estima el recurso o si se estima parcialmente la resolución tiene que estar fundamentada por los criterios jurídicos de dicho rechazo lfalta de causalidad, no se cumplen los criterios del del mobbing, etc.)

* Valoración del daño psíquico y/o moral de la víctima.

\section{RESULTADOS}

\section{Abordaje psicolegal}

Victimología y evaluación pericial del mobbing

Uno de los grandes problemas a la hora de evaluar el daño psíquico resultante del acoso es la inespecificidad de los síntomas, ya que pueden formar parte de varias categorías diagnósticas. Las investigaciones ponen de relieve que a nivel clínico la sintomatología que padecen las víctimas de acoso es muy diversa y heterogénea (Manrique-Torres, 2019; Mikkelsen, Hansen, Persson, Byrgesen y Hogh, 2020). La base del daño psíquico suele ser emocional, con síntomas del espectro ansioso-depresivo y dolencias psicosomáticas. El acoso laboral afecta a los esquemas vitales de las víctimas, lo que las lleva a padecer sentimientos de indefensión y fracaso, baja autoestima, culpabilidad y autopunición (Matthiesen y Einarsen, 2004).

La psicopatología resultante del acoso es muy heterogénea. Los cuadros de naturaleza emocional son los más característicos en este tipo de casos (Hogh et al., 2019). Debido a lo difuso de los cuadros emocionales estudiados, un diagnóstico prototípico en este tipo de situaciones es el 
Trastorno Adaptativo, siendo un diagnóstico conservador en aquellos casos en los que la víctima no desarrolla una sintomatología con la intensidad suficiente para ajustarse a los criterios TEPT (Mikkelsen y Einarsen, 2002; Tehrani, 2004) o TEPC (Organización Mundial de Salud [OMS], 2018). Precisamente gran parte de la línea de investigación en materia de daño psíquico y acoso ha seguido la línea del trauma. Diversos estudios han señalado que las víctimas de mobbing padecían síntomas similares o incluso más graves que víctimas de eventos puntiformes lun solo evento de naturaleza traumática ajustado al criterio $\mathrm{A}$ del TEPT) (Matthiesen y Einarsen, 2004).

La hipervigilancia, hiperalerta, y desconfianza son síntomas habituales (González de Rivera y RodríguezAbuin, 2006). Al tratarse de un proceso potencialmente traumático lexposición prolongada a eventos de naturaleza aversiva e imposibilidad de escape) el trabajador puede sufrir una ruptura de su sistema de creencias que conlleve un cambio en la forma de relacionarse con el mundo y consigo mismo (OMS, 2018).

Como se ha expuesto anteriormente, la mayor parte de las estrategias de acoso son sutiles y aparentemente anodinas. Es la suma de estas estrategias lo que aporta un carácter especialmente destructivo al acoso en forma de "gota china" sobre la víctima. Esta recibe múltiples microtraumatismos que terminan por desgastar sus recursos de afrontamiento. Esto implica que lo largo del proceso de acoso la víctima intenta poner en práctica numerosas estrategias de afrontamiento hasta que se produce el agotamiento, con su correspondiente sentimiento de derrota e indefensión (Dujo, 2021; GonzálezTrijueque, 2007).

El carácter simbólico y sutil de la violencia ejercida y, en ocasiones, su manifestación intermitente dentro de un proceso continuo, implican una defensa psicológica de la víctima en forma de suspicacia e hipervigilancia que ha de distinguirse de la "paranoia". La primera es una repuesta reactiva congruente ante un estresor objetivo (elevación del arousal) (Martínez-Hernáez y MedeirosFerreira, 2010), y la segunda es un error en el sistema atribucional e interpretativo del sujeto (APA, 2014).

Una de las cuestiones más importantes dentro de la evaluación clínico-forense es el curso y el pronóstico de la sintomatología objetivada de cara a la valoración del daño como lesión o secuela. Las investigaciones al respecto han señalado que las víctimas de acoso sufren daños irreparables y modificaciones psíquicas estables. Estos cambios, fruto del impacto cognitivo y emocional del trauma, pueden implicar para la víctima mayores sentimientos de ineficacia, aislamiento, patrones obsesivos, suspicacia, hipersensibilidad, desesperanza e indefensión generalizada (Hirigoyen, 2001). La ruptura de las creencias y de la visión del mundo como un entorno estable, justo y seguro generan sentimientos de indefensión y falta de control, lo que afecta directamente a los sistemas cognitivos de los sujetos condicionando la manera que tienen las víctimas de relacionarse con los demás y consigo mismas (Janoff-Bulman, 2010).

\section{Procedimiento de evaluación pericial}

La evaluación psicológica del acoso laboral se sustenta en tres pilares fundamentales. El proceso de evaluación debe ir dirigido desde un diagnóstico de sospecha a un diagnóstico de certeza (Padial y de la Iglesia, 2002). Este proceso ha de hacerse siempre desde el paradigma del método científico, vertebrando la evaluación a través de un contraste de hipótesis (Amaya, 2019), y siempre mediante una 
aproximación multifuente y multimétodo (Echeburúa, Muñoz y Loinaz, 2011).

El primer pilar dentro del proceso de evaluación forense del acoso es el estudio del estresor supuestamente identificado como victimizante (potencialmente traumático). El objetivo de este estudio es realizar un "diagnóstico diferencial" entre el mobbing y otros estresores psicosociales (González-Trijueque, Tejero y Delgado, 2011). De esta manera se cumple la delimitación de la naturaleza del estresor, que es el primer requisito hallado en la doctrina y jurisprudencia (Dujo, 2017). Además, se ha de valorar la intensidad y severidad del estresor como agente potencialmente traumático (Dujo y González-Trijueque, 2021).

Siempre debemos partir de la idea de que el mobbing no es un conflicto puntual, ni un conjunto de tensiones cristalizadas entre compañeros o superiores. Para que exista acoso tiene que cumplirse un criterio temporal y tiene que darse el elemento subjetivo de tendenciosidad (Escudero y Poyatos, 2004; Gimeno-Lahoz, 2004). El uso arbitrario del poder o abuso directivo tal vez sea el estresor laboral más difícil de diferenciar del mobbing. El abuso de dirección se basa en un conjunto de medidas organizacionales o actuaciones empresariales no ajustadas al derecho, pero que no afectan a los derechos fundamentales del trabajador, ni a su integridad psíquica de manera directa. La intencionalidad es de nuevo un elemento diferenciador entre el mobbing y el abuso directivo, ya que mientras que en el primer caso se busca la destrucción del trabajador, en el abuso directivo se busca mejorar el rendimiento de la empresa y alcanzar unos objetivos determinados a través de unos métodos poco ortodoxos, que pueden llegar a atentar contra los derechos laborales de los trabajadores. Superiores poco democráticos, competitivos y con esquemas rígidos pueden generar ambientes con presión que terminen por menoscabar el bienestar del trabajador, pero esto de ningún modo se considera acoso. Para que sea acoso, el conjunto de presiones ejercidas deben ser continuas y deben alejarse de los propios márgenes de la actividad desempeñada. Como señala Ricoy (2013), en el abuso de poder directivo el empresario busca a través de medios inadecuados un mejor aprovechamiento de la mano de obra mediante condiciones de trabajos desfavorables para los trabajadores, pero sí favorables a sus intereses.

El segundo pilar consiste en la evaluación del estado psicológico de la víctima para determinar la existencia o no de sintomatología reactiva y, en el caso de existir sintomatología, valorar si esta configura un cuadro psicopatológico. Este punto es importante de cara a conocer la gravedad y el pronóstico (González-Trijueque et al., 2011). Esto es relevante para la determinación jurídica de la lesión psíquica y de la secuela. Mientras que la lesión es una alteración clínica de la funcionalidad de la víctima (Muñoz, 2013), la secuela es una estabilización del desajuste psicológico de al menos dos años, teniendo en cuenta posibles intervenciones terapéuticas (Echeburúa, De Corral y Amor, 2004). Dentro de este proceso se ha de descartar simulación y valorar las variables moduladoras (concausas) que puedan ser factores de vulnerabilidad, protección y factores relacionados con la situación victimizante (factores pretraumáticos, peritraumáticos y postraumáticos) (Dujo y González-Trijueque, 2021).

Por último, el tercer pilar de la evaluación es establecer el nexo causal o compatibilidad entre el daño encontrado y el estresor descrito. En este sentido el 
dictamen técnico ha de hacerse en términos probabilísticos debido a que el agente causal o conductas de hostigamiento suelen estar invisibilizadas, por lo que en ocasiones solo se cuenta con el testimonio de la víctima para valorar el estresor potencialmente victimizante (Borrás, 2002). En este punto intervienen la posible coexistencia de otras concausas internas o externas que modulan el daño (Dujo y González-Trijueque, 2021). Para la valoración del nexo causal, además de estudiar las variables moduladoras se han de tener en cuenta los criterios etiológico, topográfico, cronológico, cuantitativo y de continuidad (Orengo García, 2001).

\section{Legislación}

Marco legal español

En el contexto español, a diferencia del acoso sexual o el acoso discriminatorio, no existe un concepto normativo para el mobbing o acoso moral. A pesar de ello, existen mecanismos de protección que abarcan las esferas preventiva, sancionadora, reparadora y jurisdiccional. El acoso sexual y el acoso discriminatorio están íntimamente ligados al principio de igualdad y no discriminación, dimensión que ha sido cuidada y tratada desde las instituciones europeas, consolidando un potente engranaje legal y jurisprudencial. En el caso del mobbing, el bien jurídico afectado no es propiamente el principio de igualdad o no discriminación, aunque todos los tipos de acoso estén íntimamente ligados (Correa-Carrasco, 2019).

Como se ha expuesto, a pesar de no existir una definición legal, con el paso de los años se han ido incorporando referencias nominales en el Código Penal lart. 173. 1. 2. I) y en el EBEP (Estatuto Básico del Empleado Público, art. 95. 2. ol que abarcan a los diferentes tipos de acoso. Precisamente las carencias en la regulación del acoso se han suplido en gran medida a través de una extensa jurisprudencia y doctrina jurisprudencial que ha servido de referencia en los tribunales (Dujo, 2017).

En España, existen diferentes niveles de intervención y un amplio, aunque en ocasiones difuso, marco legislativo para tratar el acoso. Desde el punto de vista de la prevención, a pesar de una presencia análoga e inespecífica en la Ley de Prevención de Riesgos Laborales (LPRL) (art.14, art. 15. $1 .{ }^{\circ}$, art 16. $1 .^{\circ}$, art. 17, 18 y 19, art. 21. 2. ${ }^{\circ}$ y art. 22) falta una mayor concreción y alusión al acoso laboral. La tutela preventiva del acoso pasa por la identificación y evaluación de las variables de riesgo como base para la creación de una acción preventiva y de vigilancia. Las empresas tienen obligaciones de protección por acción y omisión. De manera paralela a la vía judicial nos encontramos la intervención de la Inspección de Trabajo y los Criterios Técnicos (ver tabla 1)

El acoso laboral es una forma de estrés laboral con la particularidad de que no nace exclusivamente de las características inherentes al propio trabajo, sino que se ocasiona a partir de las relaciones interpersonales establecidas en el entorno laboral. La existencia de un desequilibrio de poder formal o informal y los repetidos intentos fallidos de la victima de acabar con el hostigamiento generan elevados niveles de estrés que afectan a la salud física y psíquica de la víctima IGonzálezTrijueque, 2010).

En este punto entra en juego la necesidad de protocolos antiacoso (como en el caso de algunos convenios sectoriales) con facetas preventiva y reactiva (régimen sancionadorl para garantizar la seguridad del trabajador y para asegurar que las empresas y entidades públicas cumplan sus responsabilidades preventivas. Estos protocolos han de aplicarse de manera efectiva, 
no suponiendo una exoneración de la empresa cuando el resultado es ineficaz fruto de la negligencia empresarial. Dentro de los protocolos citados se configuran medidas reactivas a través de procedimientos que permiten denunciar, y proporcionan indemnidad frente a sanciones y despidos como garantía para los trabajadores que denuncian (Correa-Carrasco, 2019).

El plano reactivo y sancionador entra en juego cuando fracasa la tutela preventiva. El poder disciplinario siempre ha de seguir los principios de proporcionalidad, seguridad jurídica y culpabilidad. Desde el punto de vista de la falta disciplinaria existen importantes carencias en la regulación legal que han sido suplidas por los convenios colectivos. La presencia de la regulación del acoso en el art. 54. 2 c, d y g del ET es inespecífico al mobbing, y de aplicación análoga al acoso discriminatorio y sexual. En cuanto a la obligación del empresario de proteger al trabajador dentro del derecho administrativo, el mobbing no está contemplado de manera específica, por lo que su regulación pasa por un abordaje genérico a través del art. 8. 11, 8. 13 y 13 bis de la Ley de Infracciones y Sanciones del Orden Social (LISOS) (Correa-Carrasco, 2019).

La tipificación del mobbing en la última reforma del Código penal español (LO 5/2010) ha sido un avance en la especificación del acoso. Es importante resaltar que la definición se circunscribe al acoso vertical y a los supuestos más graves en base a la intensidad que deriva de los actos (Correa-Carrasco, 2019). Igualmente se pone el foco en el acosador, individualizando su responsabilidad. El tipo penal exige una duración e intensidad, una intencionalidad dañina y una superioridad jerárquica o fáctica.

Dentro de la tutela reparadora, los daños producidos por el acoso deben ser subsanados por el sistema de protección social en función de la contingencia correspondiente. En la actualidad, bajo criterio doctrinal, los daños derivados del mobbing entran en la categoría de accidente laboral lart. 156. 2.e. de la Ley General de la Seguridad Social) por lo que es necesario delimitar la causalidad de la patología y descartar la existencia de concausas o vulnerabilidades previas implicadas en la etiología de la enfermedad (Correa-Carrasco, 2019). Precisamente delimitar el daño psíquico y su etiología es una de los núcleos fuertes del informe pericial psicológico, a la hora de valorar el daño como elemento objetivo probatorio constitutivo de acoso (GonzálezTrijueque, 2010).

Puesto que la responsabilidad del empresario es ser garante de los derechos del trabajador, su incumplimiento (art. 164 Ley General de la Seguridad Social) acarrea una carga indemnizatoria compatible con todas las demás. Aunque parte de la doctrina indica que, si el empresario no era conocedor de la situación de acoso, este queda exonerado de la responsabilidad, otros pronunciamientos señalan que dicha exención de responsabilidad solo puede llevarse a efecto cuando el empresario ha hecho todo lo posible para evitar el resultado lesivo. Existe la posibilidad de que el daño también se repare por la vía civil o patrimonial. Las indemnizaciones por daños morales son autónomas y complementarias. Para tal fin desde el prisma de la responsabilidad civil en casos de daños psicofísicos/morales se tomará de referencia el baremo previsto para los accidentes de tráfico y el baremo de la LISOS (Correa-Carrasco, 2019).

En cuanto a la tutela jurisdiccional, en los últimos años se ha producido una mejora en la dinámica relativa a la tutela de los derechos fundamentales, a través de procedimientos más flexibles que facilitan el acceso 
de las víctimas a protección efectiva. Se han producido mejoras en las competencias jurisdiccionales del orden social en los casos de acoso horizontal. Cabe destacar que dentro de la necesidad de relación laboral en un supuesto de acoso esta relación aparte, de ser extensible a la vinculación orgánica, también lo es a la funcional. Dentro de las garantías a la víctima, junto con las medidas cautelares comprendidas en los art. 180.1 y 180.4 de la LRJS (Ley Reguladora de la Jurisdicción Social), se encuentran las garantías específicas legales relativas a la modulación de la carga probatoria y la confidencialidad del testimonio (Art. 177.4 LRJS). A través de la inversión de la carga de la prueba, el denunciante debe presentar tan solo un principio de prueba, debiendo ser el demandado el encargado de neutralizar la evidencia de acoso (Correa-Carrasco, 2019).

Tabla 1. Regulación del mobbing en España

\begin{tabular}{|c|c|}
\hline MARCO DE REGULACIÓN & ARTÍCULOS \\
\hline Constitución española del 27 de diciembre de 1978 & Artículos 10, 14, 15, 18, 40.2 y 43 . \\
\hline $\begin{array}{l}\text { Real Decreto Legislativo 2/2015 de } 23 \text { de octubre por el que } \\
\text { se aprueba el texto refundido de la Ley del Estatuto de los } \\
\text { Trabajadores }\end{array}$ & $\begin{array}{l}\text { Art.4.2, Art.18, Art.20.3, Art.39.3, Art.40, Art.41, Art.50 y } \\
\text { Art.96.11 }\end{array}$ \\
\hline Ley de Prevención de Riesgos Laborales (LPRL) & Art.14, Art. $15.1^{\circ}$, Art $16.1^{\circ}$, Art.17, 18 y 19 , Art.21.2 ${ }^{\circ}$ y Art.22 \\
\hline $\begin{array}{l}\text { Real Decreto Legislativo 2/1995 de } 7 \text { de abril, por el que se } \\
\text { aprueba el texto refundido de la Ley de Procedimiento Laboral }\end{array}$ & $\begin{array}{l}\text { Capitulos XI } \\
\text { Art.177 y Art.180 }\end{array}$ \\
\hline $\begin{array}{l}\text { Real Decreto Legislativo } 5 / 2000 \text { de } 4 \text { de agosto por el que se } \\
\text { aprueba el texto refundido de la LISOS }\end{array}$ & 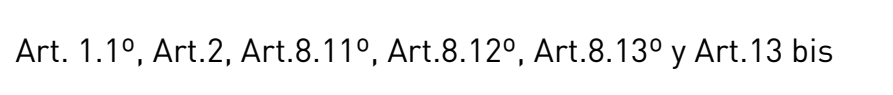 \\
\hline $\begin{array}{l}\text { Real Decreto Legislativo } 5 / 2015 \text { de } 30 \text { de octubre por el que } \\
\text { se aprueba el texto refundido de la Ley del Estatuto Básico del } \\
\text { Empleado Público }\end{array}$ & $\begin{array}{l}\text { Art. } 14 \mathrm{~h} \\
\text { Art.53.4 y Art.54.1 Art.95.2. b y Art.96 }\end{array}$ \\
\hline $\begin{array}{l}\text { Ley } 29 / 1998 \text { de } 13 \text { de julio reguladora de la Jurisdicción } \\
\text { Contencioso-Administrativa }\end{array}$ & Art.114 y ss. \\
\hline Código Penal. Ley Orgánica 5/2010 & Art. 173 párrafo $1^{\circ}$ y $2^{\circ}$ y Art. 177 \\
\hline Código Civil & Art.1101 y Art.1089 \\
\hline Criterio Técnico 34/2003 de 14 de marzo de 2003. & Criterio interno y vinculante \\
\hline
\end{tabular}




\begin{tabular}{|l|l|}
\hline \multicolumn{1}{|c|}{ MARCO DE REGULACIÓN } & ARTícuLOS \\
\hline Criterio Técnico 69/2009 & $\begin{array}{l}\text { Sobre las actuaciones de la Inspección de Trabajo y Seguridad } \\
\text { Social }\end{array}$ \\
\hline $\begin{array}{l}\text { Notas Técnicas Preventivas } \\
\text { Criterio Técnico 104/2021 }\end{array}$ & NTP 891 y 892. \\
\hline
\end{tabular}

Tabla 2. Protección jurídica del acoso laboral

\begin{tabular}{|l|l|}
\hline Tutela preventiva & $\begin{array}{l}\text { Art.4.2. d), } 50 \text { y } 19 \text { del Estatuto de los Trabajadores. } \\
\text { Arts.14, 15, 15.1.g, } 16.1 \text { y } 22 \text { de la LPRL }\end{array}$ \\
\hline Tutela sancionadora & $8.11,8.13$ y 13 bis LISOS/ Art.173.1. párrafo $1 .^{\circ}$ y $2 .^{\circ} \mathrm{CP}$ \\
\hline Tutela reparadora & Art.156. 2.e; art.164.3 y art.42.1 LGSS. Art. 3 LPRL Arts.179.3, 183.1 y 183.3 LRJS \\
\hline
\end{tabular}

\section{Marco legal latinoamericano}

El estudio de la prevalencia en Latinoamérica está condicionado por dos factores. En primer lugar, por la falta de conocimiento acerca del acoso y su regulación (Vargas-Rodríguez y Carrillo-Guarín, 2011) que limita indudablemente su reporte $y$, por otro lado, una mayor tolerancia a la violencia debido a la normalización de ciertas conductas frente a otros países (Castillo y Cubillos, 2012), por lo que se estima que la cifra de acoso es mucho mayor que la indicada en estudios como el de Chappell y Di Martino (2006) que señalaron un $8 \%$ de trabajadores víctimas de acoso en Latinoamérica.

En el caso de Colombia, el estudio del Ministerio de la Protección Social puso de relieve en el año 2004 una prevalencia de un $19 \%$, lo que dio lugar a una mayor concienciación y necesidad de crear un marco legislativo sólido para proteger al trabajador. Con esta idea se crea la Ley 1.010 en el 2006, siendo una de las pocas leyes autónomas en Latinoamérica específica para abordar el mobbing (Oceguera, Aldrete y Ruiz-Moreno, 2009). El acoso queda definido como "toda conducta persistente y demostrable, ejercida sobre un empleado, trabajador por parte de un empleador, un jefe o superior jerárquico inmediato o mediato, un compañero de trabajo o un subalterno, encaminada a infundir miedo, intimidación, terror y angustia, a causar perjuicio laboral, generar desmotivación en el trabajo, o inducir la renuncia del mismo". En esta línea, en el Capítulo IV de la Resolución 2646 del Ministerio de la Protección Social se definió un protocolo para determinar el origen de las enfermedades derivadas del estrés (Carbajal-Orozco y Dávila-Londoño, 2013; Urresta, 2013).

El abordaje del acoso se realiza a dos niveles, el primario y el paliativo, lo que implica la necesidad de cambiar la cultura organizativa en todos los sentidos. El 
art. 9 se centra en la prevención e insta a las empresas a crear espacios donde los trabajadores puedan informar sobre el problema. La ley busca blindar la responsabilidad de la empresa a la hora de proteger al trabajador, por lo que cuando una empresa muestra actitudes tolerantes con el acoso es sancionada. Cuando se le notifica a la empresa una posible situación de acoso esta puede activar un protocolo de conciliación. En el caso de las instituciones públicas, el encargado será el Ministerio de Protección Social, mientras que en el caso de las entidades privadas lo hará las Defensorías del Pueblo o la inspección de trabajo o de la policía VargasRodríguez y Carrillo-Guarín, 2011).

A pesar del gran avance que supone esta ley, en comparación con el resto de países latinoamericanos, presenta importantes carencias y vacíos conceptuales (Vargas-Rodríguez y Carrillo-Guarín, 2011). La primera carencia es la limitación del alcance de la ley a las relaciones laborales enmarcadas en contratos laborales, lo que deja fuera a otro tipo de contratos, como el de prestación de servicios. Otra carencia, y tal vez la más significativa, es la necesidad plasmada en la ley de que las conductas deben ser persistentes, demostrables y públicas. La necesidad de que las conductas sean públicas, y por tanto de alguna manera observables, choca frontalmente con el carácter sutil y silencioso de las conductas constitutivas de acoso, lo que dificultaría su demostración jurídica a través de esta especificación de Ley 1.010. Por último, a nivel correctivo, la empresa se debe responsabilizar del $50 \%$ de los gastos de tratamiento, lo cual a efectos prácticos es insuficiente debido a la gravedad de las consecuencias para la salud derivadas del mobbing, además de la responsabilización implícita que conlleva que la víctima deba pagarse la mitad de su tratamiento. Igualmente, la ley presenta carencias en aspectos de prevención sobre los aspectos organizaciones de riesgo asociados al acoso (VargasRodríguez y Carrillo-Guarín, 2011). El Ministerio de Trabajo de Colombia publicó un estudio donde se señala que las denuncias bajaron de 1220 en 2012 a 361 en 2014 , como consecuencia de los procesos de conciliación y una mayor conciencia del problema.

En el caso de Chile, aunque el acoso sexual en el trabajo está regulado legalmente desde el año 2005 (Ley 20.005 del 18 de marzo de 2005), es mediante la Ley 20.607 del 2012 cuando se intenta cubrir el vacío legal existente en la regulación del acoso laboral (Caamaño y Ugarte, 2014). Esta ley contempla el mobbing en su artículo primero y la modificación del artículo $2^{\circ}$ del Código del Trabajo de una manera amplia y poco específica:

Asimismo, es contrario a la dignidad de la persona el acoso laboral, entendiéndose por tal toda conducta que constituya agresión u hostigamiento reiterados, ejercida por el empleador o por uno o más trabajadores, en contra de otro u otros trabajadores, por cualquier medio, y que tenga como resultado para el o los afectados su menoscabo, maltrato o humillación, o bien que amenace o perjudique su situación laboral o sus oportunidades en el empleo (Ley 20.607 del 8 de agosto de 2012, art.1).

Desde el punto de vista sancionador el acoso implica la extinción del contrato laboral, pudiendo el trabajador solicitar la indemnización correspondiente (art. 171). En este mismo artículo se recogen las sanciones relativas a las denuncias falsas. Entre las carencias a más relevantes dentro de esta ley destacan la ausencia de sanciones de carácter administrativo, y la ausencia de directrices para la creación de reglamentos internos 
que promuevan la protección de víctimas y trabajadores (Caamaño y Ugarte, 2014).

Lanata (2018) señala que una de las principales carencias es que no se ha contemplado en la legislación las consecuencias que puede ocasionar el acoso, especialmente en la víctima. Esto abre el debate acerca de la consideración del acoso como enfermedad profesional o accidente de trabajo. Si consideramos que el acoso laboral es un fenómeno ligado al ejercicio de la actividad profesional, podría considerarse, en base a lo estipulado en el art. 7 de la Ley no 16.744 , como enfermedad profesional, ya que las consecuencias en la salud del trabajador tienen su origen en el ejercicio de su profesión (causa directa). Sin embargo, para considerar que es una enfermedad profesional, las conductas de acoso deberían formar parte del riesgo implícito de la actividad laboral.

En el marco legislativo chileno las consecuencias del trabajador producidas por el mobbing no se consideran jurídicamente enfermedad profesional, ya que se entiende que no son el resultado del ejercicio de la profesión, sin embargo, la patología o incapacidad ocasionada si puede encuadrarse como accidente de trabajo (art.5 de Ley $n^{0} 16.744$ ) lo que implica que la empresa tiene la responsabilidad de velar por la salud del trabajador, ya que se entiende que el acoso no forma parte indivisible de la actividad laboral, lo que exige una prevención efectiva (Lanata, 2018).

Con fecha 11 de junio de 2019 ocho diputados presentaron una moción parlamentaria mediante Proyecto de Ley (boletín n 12695-13), titulado “Modifica el Código del Trabajo y el Código Penal en materia de caracterización, investigación y sanción del acoso laboral", que entre otras cuestiones plantea la incorporación de un nuevo artículo al Código del Trabajo, el artículo 211-G, proponiendo "protocolos de acción obligatorios para prevenir, conductas de acoso laboral en la empresa". Además, también señala la necesidad de incorporar un nuevo artículo al Código Penal (art. 420 bis), en miras a establecer las conductas de acoso laboral como constitutivas de delito (Proyecto de Ley 12.695-13, 2019). Este Proyecto de Ley no ha avanzado más en su tramitación, probablemente debido al estallido social de octubre de 2019, y la posterior pandemia sanitaria iniciada en marzo de 2020.

En Venezuela no existe una regulación específica. Como ha ocurrido históricamente en los países con un marco legal deficitario en cuanto a regulación, el criterio doctrinal ha sido la brújula inequívoca en la configuración del fenómeno en Venezuela. El amparo legal se sustenta en la Ley Orgánica Procesal del Trabajo (LOPTRA), la Constitución de la República Bolivariana de Venezuela (CRBV), el Reglamento de la Ley Orgánica del Trabajo (RLOT), la Ley Orgánica de Prevención, Condiciones y Medio Ambiente de Trabajo (LOPCMAT) y la Ley Orgánica del Trabajo (LOT). En el 2007 se promulgó la Ley Orgánica sobre Derecho de las Mujeres a una Vida Libre de Violencia, ley que puede ser el punto de partida para una legislación más específica en materia de mobbing (Nava y Fernández, 2010; Ochoa y Layedra 2019).

En Uruguay nos encontramos una situación parecida, donde el mobbing (o acoso moral) es un concepto jurídico indeterminado (Trujillo y de Franco, 2016). A pesar de no existir una regulación específica para abordar el mobbing, el trabajador está amparado por normas nacionales y diversos mecanismos de protección. En cuanto a las normas nacionales destacan los artículos 
$7^{\circ}, 36^{\circ}, 44^{\circ}, 53^{\circ}, 54^{\circ}$ y $72^{\circ}$ de la Constitución, todos ellos garantes de derechos fundamentales de la persona y el derecho al trabajo. En el ámbito civil el art. 1291 del Código Civil abarca el principio de buena fe en los contratos laborales. Otros mecanismos de protección posibles es la intervención de la Inspección General del Trabajo por denuncia de parte o intervención de oficio. La Ley 16.045 relativa a la discriminación por razón de sexo en el trabajo (igualdad de trato y oportunidades) puede aplicarse de manera análoga en casos de mobbing (Giuzio, 2011). Lo mismo ocurre con la Ley 17.817 sobre racismo y otras formas de discriminación, la Ley anticorrupción 17.060 y la Ley 18.561 reguladora del acoso sexual en el trabajo (Trujillo y de Franco, 2016).

En el caso de Ecuador, aunque en noviembre de 2017 la Asamblea Nacional expidió la Ley Orgánica Reformatoria de la Ley Orgánica del Servicio Público (LOSEP) y se reformó el Código del Trabajo para Prevenir el Acoso Laboral, no hay una regulación específica del acoso en su marco legislativo. (Torres et al., 2019). En Ecuador, el abordaje del acoso estaría muy arraigado a su propio texto constitucional, pero de una manera generalista, haciendo alusión a los derechos universales de dignidad, integridad individual y colectiva, igualdad y no discriminación. Por lo tanto, el acoso laboral se entendería como un fenómeno que viola los derechos fundamentales de los trabajadores (Sánchez, 2017). Concretamente, el acoso laboral puede ser considerado un acto discriminatorio desde un prisma sindical lart. 11.3 de la Constitución Ecuatoriana). En la reforma del Código del Trabajo citado, en su artículo 46, se desarrolla una definición del acoso en todas sus formas (vertical y horizontal), en el 36 se especifican las obligaciones del empresario en materia de protección y en el 44 se condena de una manera más explícita el acoso, tanto por acción como por omisión. Finalmente, y dentro de la LOSEP, el acoso laboral, si se demuestra el nexo causal, sería motivo de extinción del contrato laboral lart. 172 y 173) y de indemnización (art. 195.3) (Torres et al., 2019).

La realidad mexicana es similar al de sus vecinos del sur. La Ley Federal del Trabajo introdujo la definición del acoso en el 2012, siendo el primer paso para diferenciar el acoso laboral del acoso sexual en el trabajo. La gran limitación de esta definición es que se limita a castigar las conductas en términos de subordinación, es decir, relativas al acoso laboral vertical descendente (Morales, 2016).

En Perú no existe una regulación específica, ni el ámbito privado y público, pero si existen dispositivos que, por analogía, pueden aplicarse como normativa garante de los derechos de los trabajadores. Ante la falta de definición específica del acoso, el cuerpo doctrinal ha servido de referente jurídico en su tratamiento. Dentro del ámbito privado, del marco regulador se pueden extraer dispositivos análogos en la Ley de Productividad y Competitividad Laboral lart.16 [extinción del contrato], art.25 [causas de despido], art.30 [supuestos de hostigamiento] y art. 35 [respuesta del trabajador ante el hostigamiento]). Ante una situación de acoso se podrá solicitar la intervención del Ministerio de Trabajo (MINTRA) para una inspección judicial (Molero-Suárez, 2008).

En el ámbito público, destaca el Decreto Legislativo $n^{\circ} 276$ (Ley de Bases de la Carrera Administrativa) en su artículo 8 en referencia a la prohibición de conductas de presión, amenaza o acoso por parte del servidor público en el contexto laboral. También pueden encontrarse normativa análoga en la Constitución, la Ley del Servicio 
Civil, Ley no 30.057 (art. 85 y 87) y la Ley de Seguridad y Salud en el Trabajo (Ley 29.783) dentro del derecho administrativo, en materia de prevención por parte del empleador. (art. 49, art. 73) (Molero-Suárez, 2008).

Argentina posee uno de los marcos legislativos más amplios, aunque la mayor parte de las normas son de carácter provincial y público. Destacan la Ley 1.225 en la Ciudad Autónoma de Buenos Aires, la Ley 5.349 (Jujuy), la Ley 13.168 (provincia de Buenos Aires), la Ley 4.245 del 2005 en Misiones, la Ley 7.006 (provincia del Chaco), la Ley 7.232 en Tucumán y la Ley 12.434 en Santa Fe (Itati, 2017).

Entre otras medidas, en el año 2005 se habilitó una oficina para recibir denuncias de violencia en el trabajo dependiente de la Fiscalía Nacional de Investigaciones Administrativas. La ausencia de un marco legislativo no implica que los derechos de los trabajadores no estén amparados por otras leyes de protección genéricas. En el caso de la Constitución Nacional destacan los artículos 14 bis (condiciones dignas de trabajo), Art. 16 (igualdad), Art. 41, 43 y 75. A nivel nacional, aunque no se recoge el acoso de manera específica, la Ley Antidiscriminación 23.592, la Ley 25.164 y el Real Decreto 214 de 2006 (Convenio Colectivo de Trabajo General de la Administración Pública Nacional) son los encargados de proteger a los trabajadores de la Administración Pública Nacional frente a la violencia laboral (Itati, 2017). A nivel privado destaca La ley del trabajo $n^{0} 20.744$ encargada de regular la obligaciones y derechos de las partes. Por su parte, la Ley de Riesgo en el trabajo $n^{0} 24.557$ y la Ley Integral a las Mujeres N. ${ }^{\circ} 26.485$ por analogía puede llegan a cubrir supuestos relacionados con el acoso laboral.

Tabla 3. Marco legal latinoamericano

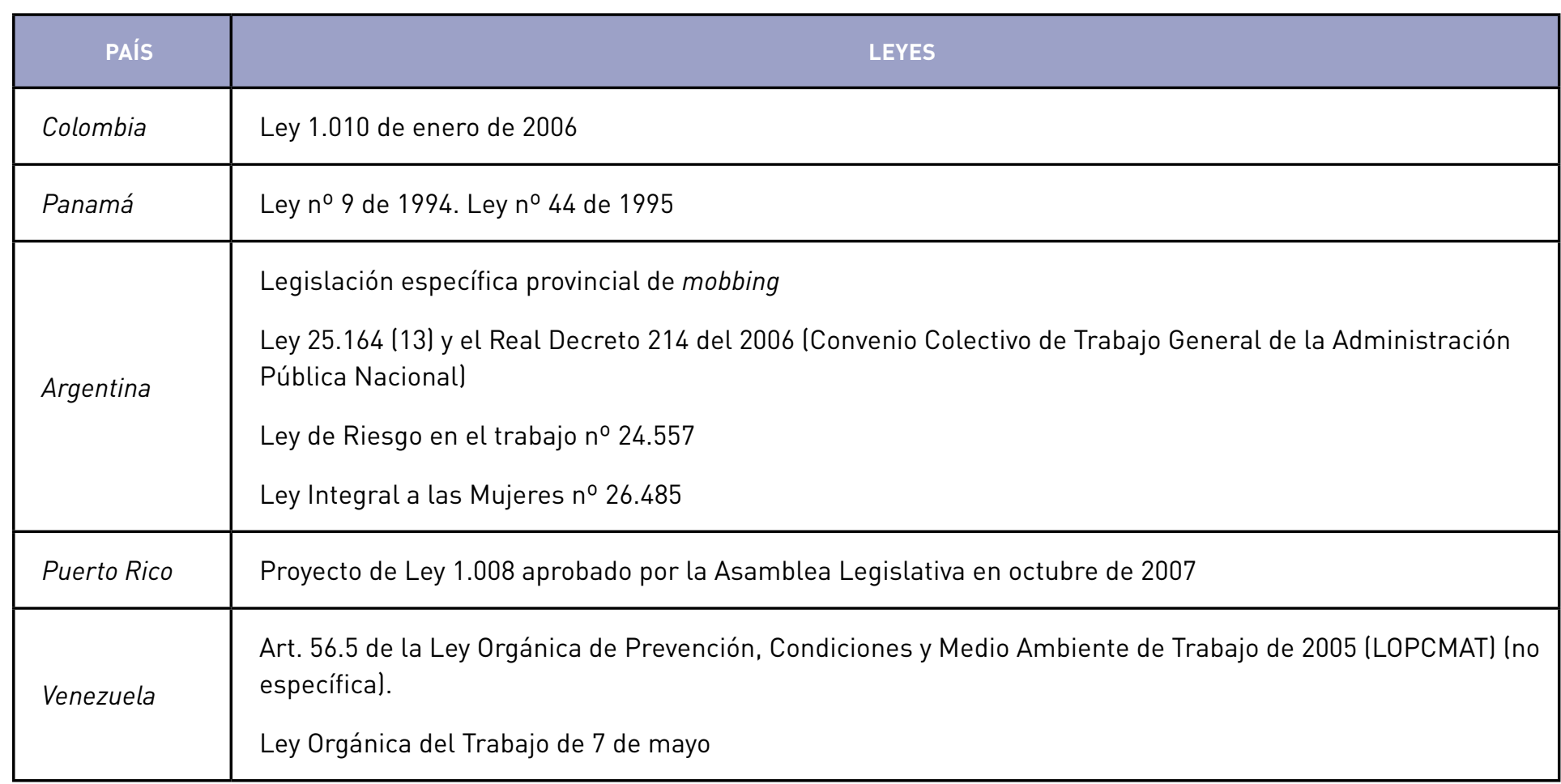




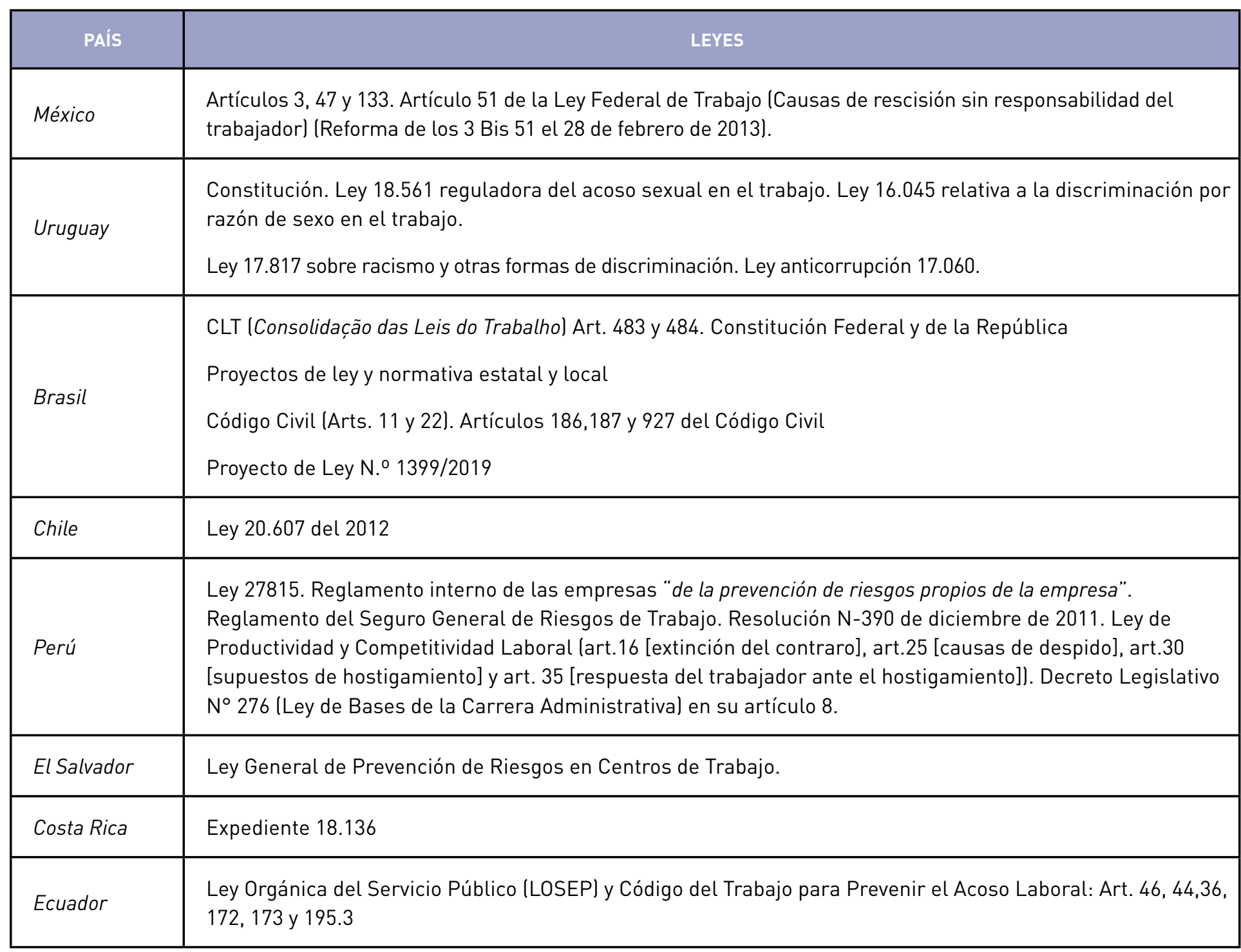

Nota: Adaptado a partir de Dujo et al., (2019, p.301)

Por último, Brasil, al igual que ocurre en Argentina, posee una amplia red de leyes de carácter estatal y local, pero carece de legislación federal. A pesar de ello existe un ordenamiento jurídico extenso garante de los derechos de los trabajadores. A nivel general destacan el Código Civil (Art. 11 y 22), la Constitución Federal (Art. 5, Inciso X), la Constitución de la República de Brasil (inciso III y IV) y el CLT (Consolidação das Leis do Trabalhol en sus artículos 482 y 483, así como numerosos Proyectos de Ley como el 4.593/09, el 7.202/2010 o el Proyecto de Ley Federal 6.757/2010. Como se ha expuesto anteriormente el peso de la legislación en mobbing o assedio moral recae en la esfera estatal y municipal. Entre las leyes más importantes destacan: Ley $n^{0} 3.921$ de Rio de Janeiro del 2002, Ley 12.250 contra el asedio Moral del Estado de Sao Paulo del año 2007, la Ley Complementaria 12.561 de Río Grande de Sul y Ley N. ${ }^{\circ} 1.163 / 00$ del 
municipio de Iracemápolis (São Paulo) (Oceguera, la vulnerabilidad previa de la víctima (concausa), aspecto Aldrete y Ruíz-Moreno, 2009).

\section{Repercusiones forenses y doctrina comparada}

Resultado del estudio jurisprudencial del Tribunal Supremo español

El $62 \%$ de las desestimaciones están motivadas por la consideración de los tribunales de que el conflicto existente, aunque sea de naturaleza laboral, no se ajusta a los criterios correspondientes al fenómeno mobbing. La presencia de los informes psicológicos periciales es relevante porque determinan el estresor y su potencial traumático y la lesión o secuela psíquica de la víctima (hipótesis de cuantificación y semejanza). Estos aspectos son de gran relevancia ya que pueden ser la base para posibles reclamaciones indemnizatorias y un referente para el establecimiento del daño moral por parte del juez. Igualmente, los informes periciales tienen relevancia de cara a valorar indispensable en la valoración de la causalidad entre el estresor y el daño psíquico (Tribunal Supremo [Sala de lo Contencioso-Administrativo, Sección 70]. Sentencia de 15 de noviembre de 2010). En materia de indemnización, se desestiman los recursos de casación cuando se entiende que el resarcimiento indemnizatorio se ha resuelto en estancias inferiores. El establecimiento del nexo causal entre el estresor (potencialmente lesivo) y el daño moral resultante es el eje vertebral del tratamiento jurídico del mobbing en los Tribunales españoles (Tribunal Supremo [Sala de lo Contencioso-Administrativo, Sección 607. Sentencia de 24 de enero de 2014; Tribunal Supremo [Sala de lo Social, Sección 10]. Sentencia de 4 de marzo de 2014; Tribunal Supremo [Sala de lo Social, Sección $1^{\circ}$ ]. Sentencia de 23 de noviembre de 2010; Tribunal Supremo [Sala de lo Contencioso-Administrativo, Sección $6^{\circ}$ ]. Sentencia de 9 de abril de 2015).

Tabla 4. Diagnósticos hallados en la muestra representativa

\begin{tabular}{|l|l|l|}
\hline DIAGNóSTICO & N.0 DE SENTENCIAS & PORCENTAJE \\
\hline Sintomatología ansioso depresiva/trastorno adaptativo mixto & 19 & 59,37 \\
\hline Ansiedad & 4 & 12,5 \\
\hline Trastorno de estrés postraumático & 2 & 6,25 \\
\hline No consta & 7 & 21,87 \\
\hline
\end{tabular}

Tabla 5. Distribución de la muestra estudiada por jurisdicción ( $N=32$ )

\begin{tabular}{|l|l|l|}
\hline JURISDICCIÓN & N.O DE SENTENCIAS & PORCENTAJE \\
\hline Social & 11 & 34,37 \\
\hline Penal & 5 & 15,62 \\
\hline
\end{tabular}




\begin{tabular}{|l|l|l|}
\hline JURISDICCIÓN & N. ${ }^{\circ}$ DE SENTENCIAS & PORCENTAJE \\
\hline Civil & 1 & 3,1 \\
\hline Contencioso-administrativa & 15 & 46,87 \\
\hline
\end{tabular}

Análisis de los resultados de sentencias, doctrina comparada y jurisprudencia

El acoso laboral ha sido estudiado por múltiples disciplinas, desde la psiquiatría hasta la psicología, el derecho y la sociología. Se trata de una realidad que ha ganado protagonismo e interés internacional debido al profundo impacto socioeconómico de sus consecuencias (Hogh et al., 2019). Aunque existen diferentes denominaciones para este fenómeno, las diversas definiciones existentes definen el mobbing como un conjunto de acciones de naturaleza heterogénea y hostil que ocurren de manera reiterada y frecuente durante un periodo de tiempo determinado en el contexto laboral (relación funcional) y que tienen como objetivo la destrucción del trabajador (Fidalgo et al., 2009).

En la doctrina y jurisprudencia española existen una serie de elementos definitorios fundamentales en la configuración del acoso. En relación a la naturaleza hostil de las conductas nos referimos a un conjunto de acciones degradantes, intimidantes, ofensivas o humillantes susceptibles de atentar contra la esfera física, psíquica o moral de la víctima. Las situaciones de acoso pueden manifestarse a través de distintas acciones y comportamientos (ver tabla 6) (GonzálezTrijueque, 2007), tanto de tipo reactivo como inhibitorio (Pérez-Bilbao et al., 2001), desarrollándose en un proceso variable pero enmarcado en fases delimitadas que desembocan en la destrucción final del trabajador.
Una de las cuestiones clave para distinguir el acoso de otros fenómenos es la reiteración en el tiempo. Las conductas constitutivas de hostigamiento de manera aislada suelen ser anodinas y potencialmente no lesivas. Es la suma de las conductas a lo largo del tiempo lo que confiere el potencial destructivo a las estrategias de acoso. Se debe apostar por un criterio flexible a la hora de determinar los márgenes de tiempo necesarios para poder afirmar que estamos ante un proceso de acoso. Al tratarse de un proceso heterogéneo y en el que confluyen muchas variables, optar por un criterio rígido sería actuar en contra de la víctima (Dujo et al., 2019). Estas conductas han de producirse en el contexto de trabajo la través de una relación orgánica o funcionall y que tengan como motivación (intencionalidad) la destrucción o abandono del trabajador. La tendenciosidad es considerada como el elemento subjetivo en la configuración del acoso que, aunque es indivisible de su configuración jurídica, en la práctica resulta muy difícil de demostrar (Correa-Carrasco, 2019).

El acoso, desde el punto de vista jurídico constituye un atentado contra los derechos fundamentales de las personas. El mobbing atenta contra la dignidad e integridad de la víctima (Hirigoyen, 2001) siendo necesario distinguir entre daño psíquico y daño moral. El propio Tribunal Constitucional señala que el daño moral no requiere de daño psíquico o físico. El nexo causal es la base para delimitar el resarcimiento y la responsabilidad del empresario. 
Tabla 6. Estrategias de acoso psicológico

\begin{tabular}{|l|l|}
\hline Acciones contra la reputación o la dignidad personal & $\begin{array}{l}\text { Conductas dirigidas a ridiculizar y dañar la dignidad y la reputación del } \\
\text { trabajador mediante burlas y comentarios injuriosos sobre su aspecto } \\
\text { físico, valores, gestos o ideología. }\end{array}$ \\
\hline Acciones contra el ejercicio del trabajo & $\begin{array}{l}\text { Puede conllevar un exceso de trabajo, tareas muy complejas o difíciles } \\
\text { de ejecutar, trabajos monótonos o por debajo de la cualificación del } \\
\text { trabajador. Estas acciones pueden implicar conflictos de rol, órdenes } \\
\text { contradictorias o negación de medios para la realización de la tarea. }\end{array}$ \\
\hline Manipulación de la comunicación o la información & $\begin{array}{l}\text { No se le informa sobre sus obligaciones, sus funciones, su responsabil- } \\
\text { idad, la metodología laboral y cantidad y calidad del trabajo. Se hace un } \\
\text { uso hostil de la comunicación criticándole o, por el contrario, haciéndole } \\
\text { el vacío. Se maximizan los errores y se minimizan los aciertos. }\end{array}$ \\
\hline Acciones de inequidad & $\begin{array}{l}\text { Diferencias en la remuneración, distribución no equitativa del trabajo y } \\
\text { trato diferencial desfavorable }\end{array}$ \\
\hline Medidas organizativas & $\begin{array}{l}\text { Rechazo público. Se rebaja su nivel en el organigrama y no se respeta su } \\
\text { jerarquía (salto de mando). }\end{array}$ \\
\hline
\end{tabular}

Adaptada de González-Trijueque et al. (2014)

Las estrategias de acoso son variadas y en ocasiones difusas o anodinas. Es precisamente el criterio temporal de persistencia y el de sistematicidad el que otorga a los actos el potencial lesivo. No se trata de actos aislados, sino que están conectados y unidos por la intencionalidad dañina. Es esta intención la que confiere sentido al conjunto de estrategias de acoso. Además, algunas conductas como, por ejemplo, la difusión de rumores, más que un hecho puntual constituyen un estado, por lo que no solo es importante valorar las posibles conductas, sino también el potencial clima hostil y de intimidación que se crea. La doctrina distingue y categoriza las conductas de acoso en actos que buscan minar la autoestima y la esfera personal del trabajador, actos que buscan destruir la reputación personal, actos que buscan socavar la reputación profesional y actos orientados a aislar e impedir las comunicaciones (Correa-Carrasco, 2019).
El acoso tiene como objetivo crear un entorno intimidatorio, degradante, hostil y humillante para el trabajador. En materia de bienes jurídicos, el proceso de acoso, en esencia pluriofensivo, atenta contra la integridad moral lartículo 15 de la CE), la dignidad personal y profesional (artículo 10 de la Constitución Española, en adelante CE) pudiendo igualmente atentar contra la salud psicofísica, incumpliendo el derecho del trabajador a la protección de su salud laboral (artículos 40.2 y 43 de la CE). Independientemente del daño psíquico, el acoso siempre será una violación de la dignidad personal del trabajador. Igualmente, el potencial lesivo puede atentar contra la libertad de expresión o comunicación del trabajador lart. 20), el derecho fundamental de igualdad y no discriminación (art. 14) y el derecho al honor y la imagen (art. 18. 1).

En este punto es importante destacar, que, aunque no siempre existirá un daño psíquico en la víctima, el 
acoso implica por definición la existencia de un daño moral. Mientras que la valoración del daño moral corresponde a la persona que juzga, la evaluación del daño psíquico corresponde al psicólogo forense (González-Trijueque et al.,2011).

Que no haya daño psíquico no implica que no se haya producido el hecho lesivo. La existencia o no de acoso no puede depender de las características personales (resiliencia/vulnerabilidad) de la víctima. La evaluación del daño psíquico tiene dos funciones primordiales, la valoración indirecta de la existencia de un conjunto de actos de hostigamiento y su potencial lesivo (González-Trijueque et al., 2011), y las consecuencias asociadas a la responsabilidad del victimario (Correa-Carrasco, 2019).

Todos los estudios, y así lo recoge la doctrina jurisprudencial, concuerdan en afirmar que el acoso produce tanto daños de naturaleza psíquica (STSJ de la Comunidad Valenciana del 25 de septiembre de 2001; Audiencia Provincial de Guipúzcoa de 29 de marzo de 2007), como física (de naturaleza psicógena) con una afectación funcional muy relevante tanto en la esfera laboral como social, familiar y personal. A veces el estresor origina una lesión y en otras ocasiones agrava una lesión o condición previa del trabajador. No todo el daño psíquico que presente el trabajador tiene por qué tener una etiología laboral y no todos los daños psíquicos con etiología propiamente laboral se dan por acoso. Estos pueden tener su origen en otro estresor psicosocial (verbi gratia estrés o burnout)

Para que exista mobbing, por definición, las conductas de hostigamiento deben producirse en el lugar de trabajo. Debido a los nuevos modelos de producción es importante realizar una interpretación ajustada a los diferentes contextos organizativos laborales, partiendo de la base de que no es necesario que la relación entre víctima y victimario sea de dependencia orgánica dentro de una misma empresa, siendo suficiente la existencia de una relación funcional (Correa-Carrasco, 2019). Las propias condiciones laborales o variables organizacionales no implican, per se, la existencia de acoso. Aunque es cierto que ciertas características y déficits organizacionales favorecen o correlacionan con el aumento de los riesgos psicosociales, esto no implica una relación causal.

Mientras que la tendenciosidad (Sentencia del Juzgado de los social No2 de Girona del 19 de febrero de 2002; Audiencia Provincial de Barcelona de 15 de septiembre de 2003; Juzgado de Social N. ${ }^{\circ} 36$ de Madrid de 29 de abril de 2003) o finalidad es el elemento distintivo en la configuración jurídica del acoso, en términos prácticos su delimitación es más laxa, debido a la imposibilidad de evaluar el plano subjetivo de las motivaciones personales de la conducta del victimario. Es necesario valorar la naturaleza de las estrategias de acoso y su prolongación en el tiempo para poder extraer conclusiones acerca de la motivación subyacente (Correa-Carrasco, 2019).

Tal y como pone de relieve el Tribunal Constitucional, la vulneración de los derechos fundamentales de la víctima no puede quedar supeditada a la intención o dolo del victimario. Se enfatiza la necesidad de establecer el nexo causal entre el comportamiento antijurídico y el daño (Correa-Carrasco, 2019; Rangel-Rosso y Oliveira-Rocha, 2020). Precisamente una de las funciones del psicólogo forense, además de la valoración del daño psíquico, es la valoración del conjunto de actos (objetivos) que configuran el proceso de acoso para estimar el potencial lesivo y, de esa manera, poder establecer el nexo causal 
entre estresor y sintomatología. Este proceso conlleva la necesidad de realizar un diagnóstico diferencial entre el mobbing y otros estresores psicosociales de naturaleza laboral, como el burnout o el ejercicio no regular del poder directivo (González-Trijueque et al., 2011).

En el caso de Colombia, un pilar fundamental a la hora de definir el acoso es que se trata de una persecución con una clara finalidad: la renuncia del trabajador. Está persecución está integrada por un conjunto de comportamientos aparentemente anodinos que buscan humillar, desprestigiar y desmotivar al trabajador. De la misma manera que queda definido el acoso, la doctrina colombiana y la propia ley 1010 definen lo que no es acoso, estableciendo unos límites parecidos a los hallados en la doctrina y jurisprudencia española, especialmente en relación al abuso del poder directivo. Precisamente uno de los principales retos a los que deben contestar los altos tribunales en Colombia deriva de la norma que define la conducta hostigadora como "repetida y pública". Cuando las conductas se dan en privado no existe presunción de acoso laboral por lo que el demandante mediante los medios probatorios legalmente aceptados debe reforzar sus argumentos indiciarios (Camacho-Ramírez, 2018).

Al igual que ocurre en España, Uruguay, Brasil y Argentina, en Colombia se enfrentan a la dificultad probatoria de los diferentes elementos constitutivos del acoso. Un elemento en común es la consideración de que el daño producido recae inequívocamente en los derechos fundamentales del trabajador, pero no necesariamente en la esfera psíquica. Es decir, no es necesario probar que hay un daño psíquico para considerar que estamos ante un proceso de acoso, ya que los actos o conductas antijurídicas tienen entidad propia independientemente de los resultados (CamachoRamírez, 2018). La doctrina de los países citados tiene como base la necesidad de que las conductas sean reiteradas en el tiempo, sin establecer un criterio rígido de temporalidad. Otro criterio a tener en cuenta es que exista un ambiente laboral hostil e intimidante para la víctima, lo que enlaza con la necesidad de que las conductas perpetradas se produzcan en el contexto laboral.

En este punto existen discrepancias doctrinales derivadas directamente de la normativa. Mientras que en España se entiende que la relación laboral debe ser orgánica o funcional independientemente del tipo de contrato, en países como Colombia la delimitación es más difusa. La sentencia de la Corte Constitucional de Colombia (C-960 de 14 de noviembre de 2007) delimita que el núcleo de la cuestión, independientemente del tipo de contrato, son la subordinación o dependencia. La disminución de la carga de la prueba tiene su base en fomentar la garantía de los derechos del trabajador fruto de la vulnerabilidad existente en la víctima. Esto adquiere relevancia en el caso de la doctrina colombiana en los casos en los que los actos y conductas no son públicos, recayendo la carga probatoria en el demandante (Sentencia C-780 de 26 de septiembre de 2007) (Camacho-Ramírez, 2018).

Los Tribunales colombianos se han pronunciado en diversos aspectos para la protección jurídica de la víctima, como la prohibición del despido sin autorización cuando la persona sufre acoso laboral, la reincorporación de los trabajadores que han renunciado en el contexto de un proceso de acoso, o la denominación de falta disciplinaria gravísima. Cuando el acoso proviene de un servidor público (Camacho-Ramírez, 2018). En cuanto a la caducidad de la conducta antijurídica, a pesar de que 
la ley establece 6 meses (art. 18 de la Ley 1.010) al no tratarse una conducta de ejecución instantánea no se produce dicha caducidad (Camacho-Ramírez, 2018).

En Uruguay, como en el resto de los países citados, la doctrina y la jurisprudencia han tenido un papel regulador ante la existencia de un ordenamiento especifico en la materia. El mobbing es considerado por el Tribunal Contencioso-Administrativo como una falta "gravísima". La doctrina uruguaya entiende que para que exista acoso deben darse los siguientes elementos: una serie de actos hostiles y reiterados contra un trabajador o trabajadores perpetrados por uno o varios trabajadores. Estos actos han de darse durante un periodo de tiempo determinado. Los actos se han de producir en el desarrollo del ejercicio profesional de la víctima (contexto laborall y han de ser degradantes y potencialmente dañinos para los derechos fundamentales llaborales y personales) (Trujillo y de Franco, 2016).

En Argentina la jurisprudencia ha buscado delimitar el acoso para diferenciarlo de otros fenómenos similares. La intencionalidad resulta un elemento clave en su configuración, siendo considerado un elemento subjetivo que lo diferencia de otro tipo de violencia psicológica (Cámara Nacional de Apelaciones de Trabajo, Sala I Sentencia Def. n 87.847 del 29 de junio de 2002) En la misma línea que el resto de países estudiados, en la jurisprudencia argentina se observa, a través de diferentes sentencias, como se delimita el mobbing como un proceso de maltrato verbal deliberado y retirado en el tiempo, sistemático y con el objetivo (intencionalidad subjetiva y perversa) de aniquilar, aislar, humillar al trabajador con el objetivo de hacer que abandone el puesto de trabajo. La doctrina se expresa igualmente en términos de responsabilidad del empresario en materia de resarcimiento.
La doctrina en Brasil sigue la misma línea, siendo necesarias una serie de condiciones para poder hablar de acoso en el análisis jurídico. El mobbing es entendido como una práctica continuada de actos de violencia contra un trabajador en la que participa el ofensor, el ofendido y los propios compañeros (espectadores). Esta violencia puede implicar aislamiento y ausencia de comunicación, ataque a la reputación y a la dignidad profesional del trabajador. Los actos perpetrados resultan humillantes y se dan de manera sistemática y reiterada en tiempo, pudiendo afectar a la identidad, la salud física y psíquica del trabajador y sus diferentes esferas vitales Para hablar de mobbing el conjunto de actos debe darse en el marco del trabajo o las relaciones laborales, la conducta hostigadora debe ser intensa, reiterada y sistemática, debe de producir un daño y tiene que existir una intencionalidad de dañar (Rangel-Rosso, Barroso y Oliveira-Rocha, 2018). Mientras que el daño moral asociado a lesión de los derechos fundamentales del trabajador es un elemento definitorio del acoso, el daño psíquico no es necesario para configurar el mobbing (Castro, 2014).

A modo de resumen y en líneas generales se puede afirmar que la doctrina y la jurisprudencia han sido vitales para la inclusión del corpus científico-jurídico del acoso en el ámbito de la protección de los derechos laborales. Aunque no hay un marco regulador específico en Latinoamérica, la fuente doctrinal ha servido para cubrir parcialmente estas necesidades. A pesar de que las aproximaciones normativas son generalistas (acoso, hostigamiento, ataque a la dignidad, etc.) existe un consenso a la hora de entender que el acoso laboral requiere de una naturaleza específica lactos, conductas o situaciones hostiles y potencialmente intimidantes), 
un marco temporal (duración, frecuencia y sistematicidad), una relación laboral funcional y una intencionalidad por parte del hostigador. Teniendo de referencia estos pilares, la labor del psicólogo forense es valorar el daño psíquico de la presunta víctima, para lo que es necesario determinar el estresor y su potencial traumático, siendo indispensable analizar, no solo la naturaleza de los actos o conductas, sino también su desarrollo en el tiempo. Esto es de vital importancia porque el potencial traumático proviene tanto del tipo de estrategia de acoso como de la duración de la misma. En un segunda plano, aunque no menos importante, se ha incardinar todo le descrito teniendo en cuenta la distancia de poder entre la víctima y el hostigador (el estatus), el margen de control de la víctima (controlabilidad) y el posible apoyo social percibido. Esto es relevante ya que va a condicionar el margen de maniobrabilidad del trabajador a la hora de enfrentarse al acoso, y puede ser un elemento fundamental lvariables peritraumáticas y postraumáticas) a la hora de explicar la etiología del daño.

\section{DISCUSIÓN Y CONCLUSIONES}

A pesar de las muchas definiciones existentes, y de que el proceso de estandarización del término está aún en proceso (OIT, 2018), el acoso es definido como un conjunto de actos (fenómeno pluriofensivo) perpetrados por superiores y/o compañeros que atentan contra la integridad moral del trabajador, pudiendo afectar a su salud psicofísica. La tendenciosidad, entendida como elemento subjetivo finalista en el acoso, es la característica distintiva desde el punto de vista de la configuración jurídica del fenómeno (Tribunal Supremo [Sala de lo Social, Sección $1^{\circ}$ ] Sentencia de 14 de febrero de 2012) (Correa-Carrasco, 2019). Debido a que la construcción del término se ha nutrido de múltiples disciplinas (psicología, psiquiatría, sociología etc.), y ha ido evolucionando en la práctica doctrinal de los diferentes países, cuando se realiza una aproximación psicolegal del acoso es imprescindible diferenciar la dimensión clínica-forense de la dimensión jurídica.

Por un lado, a nivel clínico-forense resulta indispensable sofisticar los protocolos de evaluación forense con el objetivo de dar respuesta a las demandas de los tribunales en aquellas cuestiones técnicas susceptibles de ser abordadas desde el prisma de la psicología forense. En materia de victimología es fundamental seguir investigando en la sintomatología característica de este tipo de procesos de revictimización para dar respuesta al daño psíquico de la víctima y facilitar la regeneración del tejido emocional, social y laboral dañado en el marco de la justicia restaurativa. A nivel técnico-jurídico el objetivo es definir los elementos configuradores del acoso para que el sistema de protección en materia de prevención, reparación, sanción y tutela jurisdiccional sea lo más autónomo y adecuado posible.

Mientras que, para la perspectiva clínico-forense, el daño psíquico supone un elemento esencial a la hora de configurar el acoso, para la perspectiva jurídica es un elemento secundario y no necesario. Cuando estudiamos el acoso desde una óptica jurídica ponemos el foco en los bienes jurídicos protegidos tales como la dignidad, el honor y la integridad moral, cuya afectación no converge necesariamente con un daño psíquico en la víctima. Este matiz se observa tanto en la doctrina científica comparada como en el análisis jurisprudencial de los tribunales españoles. La valoración del daño psíquico adquiere relevancia como prueba indirecta de la existencia de un estresor con potencial traumático, 
desde el punto de visto victimológico e indemnizatorio (reparador), pero a nivel jurídico la existencia o ausencia de daño psíquico en la víctima no asegura o desecha la posibilidad de que haya habido una situación de hostigamiento. No todas las víctimas de acoso desarrollan sintomatología o un cuadro psicopatológico. De ser así, la configuración jurídica del acoso, y por tanto su eco en el tratamiento jurídico, dependería de la capacidad de la víctima para resistir.

Desde el punto de vista psicológico-pericial objetivar un daño psíquico implica realizar un estudio psicológico de la víctima para delimitar la intensidad, alcance y pronóstico del daño, estudiar el estresor descrito (potencial lesivo), descartar simulación y establecer un posible nexo causal entre el daño y estresor objetivado. Para ello es fundamental el estudio de las variables moduladoras (factores de vulnerabilidad y protección) ya que dicho estudio nos permite comprender la etiología de la sintomatología y explicar igualmente la ausencia de la misma. Precisamente estos elementos en la evaluación forense son fundamentales porque dan respuesta a los dos principales pilares de la configuración jurídica del mobbing: la naturaleza y temporalidad de las conductas, y el nexo causal. El estudio pericial del acoso en la medida de lo posible debe contar con fuentes complementarias de información que aporten mayor fiabilidad a la medida y resten valor subjetivo a la información aportada. El escenario más habitual es que solo tengamos acceso a la víctima, por lo que la metodología ha de ajustarse a los estándares técnicos y deontológicos de la evaluación forense del daño psíquico. En este sentido debemos diferenciar un evento estresante de un evento potencialmente traumático. Mientras que para entender el impacto del evento estresante necesitamos conocer los recursos del trabajador para entender el daño o desequilibrio, en el caso de los eventos traumáticos de elevada intensidad, a mayor objetividad e intensidad del evento, más directo será el nexo causal con el daño.

Este paradigma implica analizar todas las variables personales y situacionales que pueden estar involucradas en la etiología del daño, así como realizar un examen exhaustivo del potencial traumático del evento. Esta es la única manera de que el daño psíquico, en el caso de que lo haya, sea un indicador indirecto de la exposición de la víctima a un evento potencialmente estresante o traumático, siempre y cuando se determine una causalidad.

Como se observa en la doctrina comparada latinoamericana y la jurisprudencia española, la naturaleza y sistematicidad de la conducta de hostigamiento es el principal punto de anclaje para realizar un diagnóstico diferencial entre el acoso y otros estresores psicosociales de naturaleza laboral. Pero más allá de los elementos objetivos constitutivos del acoso, nos encontramos con el elemento subjetivo finalista: la tendenciosidad o intencionalidad de dañar. El elemento teleológico es fundamental desde el punto de vista conceptual para definir el mobbing, y diferenciarlo de otras figuras próximas como el caso de los conflictos puntuales, el uso arbitrario del poder o el burnout. A pesar de ello, a nivel práctico jurídico, debido al carácter subjetivo y la imposibilidad de valorar las motivaciones personales del victimario es motivo de discrepancia doctrinal (Correa-Carrasco, 2019).

Como señala Correa-Carrasco (2019) en base en la tutela antidiscriminatoria no se puede supeditar la presencia de una situación de acoso al propósito del acosador. Debido a la dificultad probatoria de este elemento 
subjetivo, el análisis pormenorizado de los elementos objetivos (naturaleza y temporalidad) deben bastar para concluir acerca de las motivaciones, ya que estas motivaciones son las que aportan unidad a un conjunto de conductas de hostigamiento repetidas y sistemáticas cuyo único leitmotiv es la destrucción y anulación del trabajador. A partir del estudio de las conductas y su desarrollo se evidencia que la única explicación plausible es la existencia de un plan orquestado para denigrar y destruir al trabajador

Si entendemos el mobbing como una serie de conductas de hostigamiento repetidas que en conjunto, y mantenidas en el tiempo (temporalidad), adquieren la entidad de comportamiento antijurídico que atenta contra la integridad moral del trabajador, la motivación subyacente da sentido a todo este conjunto de acciones, por lo que la intencionalidad queda demostrada indirectamente a través de la evidencia de los comportamientos antijurídicos mantenidos en el tiempo, ya que otra explicación que los justifique no tiene lugar.

Como perspectivas de futuro, y desde el punto de vista psicológico, sería necesaria una línea de investigación futura para la creación de instrumentos de medida del acoso laboral con escalas de validez y adaptación a población forense (Dujo y González-Trijueque, 2021). Otra línea de investigación de gran interés desde el ámbito de la salud, el organizacional y el psicolegal son las aproximaciones estadísticas a los métodos de medición del mobbing (León-Pérez et al., 2014) ya que aportan unas medidas menos sesgadas, lo que implica unificar criterios de cara a los potenciales planes de prevención y de intervención en los distintos ámbitos aplicativos relacionados con el acoso, incluido el jurídico.

\section{DECLARACIÓN DE CONFLICTO DE INTERÉS}

Los autores no declaran conflicto de interés. 


\section{REFERENCIAS BIBLIOGRÁFICAS}

Amaya, S. (2019). Epistemología y Psicología forense: Guía práctica para psicólogos y abogados. Editorial El Manual Moderno Colombia SAS.

American Psychiatric Association. (2014). Manual diagnóstico y estadístico de los trastornos mentales (DSM-5). Madrid, España: Panamericana.

Arenas, A., Giorgi, G., Montani, F., Mancuso, S., Perez, J. F., Mucci, N., y Arcangeli, G. (2015). Workplace bullying in a sample of Italian and Spanish employees and its relationship with job satisfaction, and psychological well-being. Frontiers in psychology, 6, 1912.

Borrás, L. (2002). El mobbing o acoso moral en el trabajo. Psicopatología Clínica Legal y Forense, 2(2), 113-120.

Caamaño, E. y Ugarte, J. (2014). El acoso laboral: tutela y prueba de la lesión de los derechos fundamentales. Iut et Praxis, 20 (1), 67-90.

Camacho-Ramírez, A. (2018). Acoso laboral o mobbing. Bogotá: Universidad de Rosario.

Carbajal-Orozco, J.G. y Dávila-Londoño, C.A. (2013). Mobbing o acoso laboral. Revisión del tema en Colombia. Cuadernos de Administración, 29 (49), 95-106.

Carnero, M. A., Martínez, B. y Sánchez-Mangas, R. (2012). Mobbing and workers' health: Empirical analysis for Spain. International Journal of Manpower, 33(3), 322-339.

Castillo, J. A. y Cubillos, Á. P. (2012). La violencia en las transformaciones de los sistemas de trabajo en Colombia. Revista de Salud Pública, 14, 84-97.

Castro, C.R. (2014). O que você precisa saber sobre o assédio moral nas relações de emprego ( $2^{\circ}$ ed.). São Paulo:LTR

Chappell, D. y Di Martino, V. (2006). Violence at work. International Labour Organization.Geneve

Correa-Carrasco, M. (2019). Acoso Laboral: Regulación jurídica y práctica aplicativa. Valencia: Tirant lo Blanch.

da Silva-João, A. L., y Saldanha-Portelada, A. F. (2016). Mobbing and its impact on interpersonal relationships at the workplace. Journal of Interpersonal Violence. https://doi.org/10.1177/0886260516662850.

Davenport, N., Schwartz, R. D., \& Elliott, G. P. (2005). Mobbing: Emotional abuse in the American workplace. Ames, IA: Civil Society Publishing.

Dujo, V. (2021). Las variables moduladoras del acoso psicológico en el trabajo: un enfoque victimológico y forense [Tesis doctoral]. Universidad Complutense de Madrid.

Dujo, V. (2017). Mobbing: victimología y repercusiones forenses. En Arce, R. (Presidencia) $X$ congreso Internacional de Psicología Jurídica y Forense. Sociedad Española de Psicología Jurídica y Forense. Sevilla.

Dujo, V. y González-Trijueque, D. (2021). Revisión de Instrumentos en Español para Medir el Acoso Laboral: Su Utilidad en la Evaluación Pericial. Anuario de Psicología Jurídica, Avance online. https://doi.org/10.5093/apj2021a16

Dujo, V., González-Trijueque, D. y García-López, E. (2019). Violencia sexual, física y psicológica en el trabajo. En García-López, E. (Ed.), Psicopatología de la Violencia: Aspectos jurídicos y evaluación criminológica. lpp. 266309). Ciudad de México, México: Manual Moderno.

Dujo, V., González-Trijueque D., Graña, J.L. y Andreu, J.M. (2020). A Psychometric Study of a Spanish Version of the Negative Acts Questionnaire-Revised: Confirmatory Factor Analysis. Frontiers in Psychology 11:1856. https://doi.org/10.3389/fpsyg.2020.01856

Echeburúa, E., De Corral, P. y Amor, P. J. (2004). Evaluación del daño psicológico en las víctimas de delitos violentos. Psicopatología Clínica, Legal y Forense, 4, 227-244.

Echeburúa, E., Muñoz, J. M. y Loinaz, I. (2011). La evaluación psicológica forense frente a la evaluación clínica: propuestas y retos de futuro. International Journal of Clinical and Health Psychology, 11(1), 141-159.

Einarsen, S. V., Hoel, H., Zapf, D., y Cooper, C. (2020). The concept of bullying and harassment at work: the European tradition. En S.V. Einarsen, H. Hoel, D. Zapf, y C.L. Cooper, (Eds.). Bullying and harassment in the workplace: Theory, research, and practice (3rd ed., pp. 3-54). CRC Press. 
Escartín, J., Rodríguez-Carballeira, A., Zapf, D., Porrúa, C., y Martín-Peña, J. (2009). Gravedad percibida de varios comportamientos de bullying en el trabajo y la relevancia de la exposición al bullying. Trabajo y estrés, 23 (3), 191-205.

Escartín, J., Rodríguez-Carballeita,A., Zapf,D. (2012). Mobbing: Acoso psicológico en el trabajo. Madrid: Editorial Síntesis

Escudero, J. F. y Poyatos, G. (2004). Mobbing: Análisis multidisciplinar y estrategia legal. Barcelona: Bosch.

Eurofound (2017). Sixth European Working Conditions Survey-Overview report (2017 update). https://www.eurofound.europa. eu/publications/report/2016/working-conditions/sixtheuropean-working-conditions-survey-overview-report

EU-OSHA (2014). La estimación del coste del estrés y los riesgos psicosociales relacionados con el trabajo: Observatorio Europeo de Riesgos Revisión Bibliográfica. Agencia Europea para la Seguridad y Salud del Trabajo. Luxemburgo.

Fidalgo, A. M., Gallego, Y., Ferrer, R., Nogareda, C., Pérez-Zambrana, G. y García-Maciá, R. (2009). Nota técnica preventiva (NTP) 854. Acoso psicológico en el trabajo: definición. Instituto Nacional de Seguridad e Higiene en el Trabajo. http:// www.insht. es/InshtWeb/Contenidos/Documentacion/ FichasTecnicas/NTP/Ficheros/821a921/854\%20web.pd

Gimeno Lahoz, R. (2004). La presión laboral tendenciosa (mobbing). Universitat de Girona.

Giuzio, G. (2011). El mobbing o acoso moral en el trabajo Un enfoque jurídico. Revista de la Facultad de Derecho, (31), 185-192.

González de Rivera, J. L. y Rodríguez-Abuin, M. (2006). Acoso psicológico en el trabajo y psicopatología: Un estudio con el LIPT-60 y el SCL 90-R. Revista de Psicología del Trabajo y de las Organizaciones, 22(3), 397-412.

González-Trijueque, D. (2007). El acoso psicológico en el lugar de trabajo: epidemiología, variables psicosociales y repercusiones forenses [Tesis doctoral]. Universidad Complutense de Madrid. https:// eprints.ucm.es/id/eprint/15361/1/T30111.pdf

González-Trijueque, D. (2010). Mobbing: aproximación al acoso psicológico en el lugar de trabajo. En E. García-López
(Dir.), Fundamentos de la psicología jurídica y forense (pp. 423-451). México: Oxford University Press.

González-Trijueque,D., Tejero,R., y Delgado, S. (2011). El mobbing desde la perspectiva de la psicología jurídica. En G.A. Hernandez-Medina (Dir.), Psicología jurídica iberoamericana (pp. 327-345), Bogotá: El Manual Moderno.

González-Trijueque, D., Tejero, R., García-López, E. y Delgado, S. (2014). Psicología Forense Laboral: Aproximación conceptual y guida práctica. En E. García-López, Psicopatología forense: comportamiento humano y tribunales de justicia (pp. 162-207). Manual Moderno

Hirigoyen,M.F. (2001). El acoso laboral en el trabajo. Distinguir lo verdadero de lo falso. Barcelona:Paidós

Hogh, A., Clausen, T., Bickmann, L., Hansen, A. M., Conway, P. M. y Baernholdt, M. (2019). Consequences of workplace bullying for individuals, organizations and society. In $P$. D'Cruz, E. Noronha, G. Notelaers, y C. Rayner (Eds.), Concepts, Approaches and Methods. Handbooks of Workplace Bullying, Emotional Abuse and Harassment, vol 2 (pp.1-24). Springer. https://doi.org/10.1007/978-981-10-6173-8_8-1

Itati,V. (2017). Legislación argentina sobre violencia laboral en organismos estatales. Revista Anales de la Facultad de Ciencias Jurídicas y Sociales, 47, 812-832.

Janoff-Bulman, R. (2010). Shattered assumptions. Simon and Schuster.

Lanata, R. G. (2018). El acoso laboral y la obligación de seguridad en el trabajo. Revista de Derecho (Valdivia), 31(1), 105-126

León-Pérez J. M., Escartín J., y Giorgi G. (2019). The presence of workplace bullying and harassment worldwide. En P.D'Cruz et al. (Eds.), Concepts, Approaches and Methods, Handbook of Workplace Bullying, Emocional Abuse and Harassment ( $1{ }^{\mathrm{a}} \mathrm{Ed}$ ). Springer. https://doi.org/10.1007/978-981-10-5334-4_3-1

León-Pérez, J. M., Notelaers, G., Arenas, A., Munduate, L. y Medina, F. J. (2014). Identifying victims of workplace bullying by integrating traditional estimation approaches into a latent class cluster model. Journal of Interpersonal Violence, 29(7), 1155-1177. 
Ley 20.607 del 8 de agosto de 2012, que modifica el código del trabajo, sancionando las prácticas de acoso laboral. Ministerio del Trabajo y Previsión Social. Recuperado de: https://www.bcn.cl/leychile/navegar?idNorma=1042709

Leymann, H. (1996). The content and development of mobbing at work. European journal of work and organizational psychology, 5(2), 165-184.

Liberati, A., Altman, D. G., Tetzlaff, J., Mulrow, C., Gøtzsche, P. C., loannidis, J. P., Clarke, M., Devereaux, P.J., Kleijnen, J. y Moher, D. (2009). The PRISMA statement for reporting systematic reviews and meta-analyses of studies that evaluate health care interventions: explanation and elaboration. Journal of Clínical Epidemiology, 62(10), e1-e34. https://doi.org/10.1016/j.jclinepi.2009.06.006

Manrique-Torres, A.M. (2019). Acoso laboral (Mobbing): Riesgo psicosocial emergente invisible. Revista Interamericana de Psicología Ocupacional, 38 (2), 127-137.

Martín-Daza, F., Pérez-Bilbao, J. y García-Silva, J. A. L. (1998). NTP 476: El hostigamiento psicológico en el trabajo: mobbing. Ministerio de Trabajo y Asuntos Sociales, Instituto Nacional de Seguridad e Higiene en el Trabajo.

Martínez-Hernáez, Á., \& Medeiros-Ferreira, L. (2010). Anatomy of a misunderstanding: wrong diagnosis of paranoid pathology in victims of mobbing. Archives of Clinical Psychiatry (São Paulo), 37(4), 167-174.

Matthiesen, S. B. y Einarsen, S. (2004). Psychiatric distress and symptoms of PTSD among victims of bullying at work. British journal of guidance \& counselling, 32(3), 335-356.

Mikkelsen, E. G. E. y Einarsen, S. (2002). Basic assumptions and symptoms of post-traumatic stress among victims of bullying at work. European journal of work and organizational psychology, 11(1), 87-111.

Mikkelsen, E.G., Hansen, A.S., Person, G., Byrgesen, M. F. y Hogh, A. (2020). Individual consequences of being exposed to workplace bullying. En S. V. Einarsen, H. Hoel, D. Zapf, \& C. L. Cooper (Eds.). Bullying and harassment in the workplace: Theory, research, and practice (3rd ed., pp. 163-208). Boca Raton: CRC Press.
Molero-Suárez, M. (2008). El acoso psicológico (mobbing) en la legislación laboral peruana: el desarrollo de un concepto. lus et Veritas, (36), 340-365.

Morales, M. A. (2016). Aproximación al acoso laboral desde la legislación comparada. Boletín mexicano de derecho comparado, 49(147), 71-98.

Muñoz, J. M. (2013). La evaluación psicológica forense del daño psíquico: propuesta de un protocolo de actuación pericial. Anuario de Psicología Jurídica, 23, 61-69. https://doi.org/10.5093/aj2013a10

Nava, Y. J., y Fernández, M. E. (2010). El mobbing o acoso moral en el trabajo y su tratamiento en Venezuela. Revista de derecho: División de Ciencias Jurídicas de la Universidad del Norte, (33), 62-95.

Oceguera, A., Aldrete, G. y Ruiz-Moreno, A. (2009). Estudio comparado de la legislación del mobbing en Latinoamérica. Política y Sociedad, 8, 83-94.

Ochoa, C.D. y Layedra, W.E. (2019). El acoso laboral desde una perspectiva doctrinal y jurídica. Revista Científica Electrónica de Ciencias Gerenciales, 42 (14), 5-13.

OIT (2018). Acabar con la violencia y el acoso contra las mujeres y los hombres en el mundo del trabajo. $107^{a}$ reunión de la Conferencia Internacional del Trabajo. Ginebra

Orengo-García, F. (2001). Perspectivas Psiquiátrico Legales en torno a la cuestión del daño y trauma psíquicos. Rescatado de http://www.sepet.org.

Organización Mundial de la Salud (2018). CIE-11. Clasificación Internacional de Enfermedades (11ªrevisión). Autor

Padial, O. y De la Iglesia, M. (2002). El mobbing como enfermedad de trabajo. Lan Harremanak. Revista de Relaciones Laborales, 7, 231-240. https://ojs.ehu.eus/ index.php/Lan_Harremanak/article/view/5828

Pérez-Bilbao, J., Nogareda, C., Martín-Daza, F. y Sancho, T. (2001). Mobbing, violencia física y acoso sexual. Madrid: I. N. de Seguridad e Higiene en el Trabajo

Proyecto de Ley. Cámara de los Diputados de Chile. Boletín N. ${ }^{\circ}$ 12695-13. Modifica el Código del Trabajo y el Código Penal 
en materia de caracterización, investigación y sanción del acoso laboral. Recuperado de https://www.camara.cl/ verDoc.aspx?prmTipo=SIAL\&prmID=48778\&formato $=$ pdf

Rangel-Rosso, R.A., Barroso, S.R. y de Oliveira-Rocha, W. (2018). Acerca de la construcción normativa del mobbing laboral en el ordenamiento jurídico brasileño. Revista General de Derecho del Trabajo y la Seguridad Social, 49.

Rangel-Rosso, R.A. y de Oliveira-Rocha, W. (2020). Del mobbing de trabajo en el ordenamiento jurídico brasileño. Revista Internacional Comparada de Relaciones Laborales y Derechos del Empleo, 2, 150-174.

Ricoy, R. (2013). Mobbing o acoso moral laboral e inmobiliario. Estrategias para su erradicación. Servicio de Publicaciones de la Universidad de Vigo: Vigo

Salas, M. L., Quezada, S., Basagoitia, A., Fernández, T., Herrera, R., Parra, M., . . Radon, K.

(2015). Working conditions, workplace violence, and psychological distress in Andean miners: A cross-sectional study across three countries. Annals of Global Health, 81(4), 465-474.

Sánchez, M. P. (2017). El mobbing o acoso moral en el trabajo: análisis del caso ecuatoriano. Killkana sociales: Revista de Investigación Científica, 1(1), 1-10.

Tehrani, N. (2004). Bullying: a source of chronic post-traumatic stress? British journal of guidance \& counselling, 32(3), 357-366.

Torres, L. D. T., Hidalgo, G. F. A., Andrade, J. R. S., Cando, J. L. M., Jama, J. M. M. y Burbano, R. D. P. (2019). El acoso laboral y su tipicidad en el ordenamiento jurídico penal como una contravención. Dilemas contemporáneos: Educación, Política y Valores, 70 (4), 1-25

Trujillo,F. y de Franco, M.S. (2016). Uruguay y España frente al mobbing: Una visión jurídica crítica. Revista de Derecho de la Universidad de Montevideo, 30, 113-134

UGT (2013). Costes Socio-Económicos de los Riesgos Psicosociales, UGT-CEC.

Urresta, M.M. (2013). Aproximaciones a una conceptualización del acoso laboral en el ordenamiento jurídico colombiano. Revista Facultad de Derecho y Ciencias Políticas, 43 (118), 387-405.

Vargas-Rodríguez, Á. M. y Carrillo-Guarín, J. E. (2011). Mobbing en Colombia alcances y limitaciones de la Ley 1010 de 2006. Revista Interamericana de Psicología Ocupacional, 30(1), 106-120.

Zapf, D., Escartín, J., Scheppa-Lahyani, M., Einarsen, S.V., Hoel, H. y Vartia, M. (2020). Empirical findings on prevalence and risk groups of bullying in the workplace. En S. V. Einarsen, H. Hoel, D. Zapf, \& C. L. Cooper (Eds.). Bullying and harassment in the workplace: Theory, research, and practice (3rd ed., pp. 105-162). Boca Raton: CRC Press.

Zapf, D. y Einarsen, S. (2001). Bullying in the workplace: Recent trends in research and practice: an introduction. European Journal of work and organizational psychology, 10(4), 369-373. 